\title{
Pesquisa acadêmico-científica nas instituições de ensino superior: do faz-de-conta à realidade do mundo digital
}

\author{
Scientific academic research in higher education institutions: from fiction to \\ the reality of the digital world
}

\author{
Mirian Maia do Amaral ${ }^{1}$ \\ Lina Cardoso Nunes ${ }^{2}$
}

\begin{abstract}
Resumo
Neste artigo apresentam-se reflexões sobre o processo de pesquisa acadêmico-científica, tomando-se por base a constatação de que as práticas utilizadas nas instituições de ensino superior geralmente não atendem às demandas da educação e da pós-modernidade. Indica-se a necessidade de se adotarem estratégias de aprendizagem mais eficazes, que permitam que esse processo seja trabalhado, desde os primeiros níveis de formação, favorecendo o diálogo, a cooperação e a interatividade entre os agentes do processo educacional. 0 pressuposto é de que os professores estejam compromissados em fornecer, aos estudantes, o instrumental básico para que a pesquisa se efetive, em consonância com os desafios do mundo digital, possibilitando-/hes 0 desenvolvimento de suas potencialidades, a fim de se tornarem artífices de seu próprio conhecimento e aprendizado.
\end{abstract}

Palavras-chave: Tecnologia da Informação e da Comunicação; conhecimento, pesquisa acadêmicocientífica.

Abstract

The article presents some reflections about academic research procedures, taking into account the fact that the practices used in higher education institutions do not meet the demands of education and post-modernity. The proposal of the authors is the substitution of traditional practices for more efficient strategies of learning which favours dialogue, cooperation and interactivity among players of the educational process, starting from elementary education. The premise is that educational actors of this process should have the commitment to provide students the use of research tools and a complete access to the digital world. This education approach will be able to develop students' potentialities and improve the conditions for them to be the craftsman of their own knowledge.

Keywords: Information and Communication Technologies, knowledge; scientific academic research.

\section{Considerações iniciais}

A Resolução $n^{\circ}$ 1, de 3 de abril de 2001, do Conselho Nacional de Educação (CNE), que estabelece normas para o funcionamento de cursos de pós-graduação lato sensu, exige de seus concluintes, para obtenção de diplomas ou certificados, a apresentação de uma monografia ou de um trabalho de conclusão de curso (TCC). Entretanto, elaborar esses trabalhos não tem se mostrado uma tarefa das mais simples, pois seu

\footnotetext{
${ }^{1}$ Mestre em Educação e Cultura Contemporânea pela UNESA. Professora de Metodologia de Pesquisa nos cursos de pós- graduação do programa FGVManagement /FGV. Endereço: Praia de Botafogo, 190-10 andar. Botafogo - CEP: 22253-900 - Rio de Janeiro, RJ - Brasil. E-mail: amaral@fgv.br

${ }^{2}$ Doutora em Educação pela UFRJ. Professora do curso de Mestrado em Educação e Cultura Contemporânea da Universidade Estácio de Sá. Endereço: Av. Presidente Vargas, 642 - 22 andar. Centro - CEP: 20071-001 - Rio de Janeiro, RJ - Brasil. E-mail: nunes.lina@yahoo.com.br

Artigo submetido em janeiro de 2007 e aprovado em maio de 2008
} 
desenvolvimento requer a adoção de procedimentos científicos. Diante do desafio de demonstrar, de forma articulada, os conhecimentos assimilados ao longo do curso, assumir a autoria das conclusões formuladas e provar os resultados alcançados mediante a utilização, processamento e análise dos materiais consultados, ressaltam Martins e Lintz (2000) que o aluno-autor da pesquisa geralmente experimenta uma série de limitações, desde os sentimentos de insegurança e ansiedade, até as relacionadas à falta de experiência com a iniciação científica, que exige um exercício intelectual na busca do conhecimento, revelador de sua leitura, reflexão e interpretação de uma realidade específica. Nessa perspectiva, Lima (2004, p. 11) afirma que:

[...]. Desprovido de intrumentos que o capacitem a agir como sujeito nos processos de ensino e aprendizagem, acomoda-se na atitude de reproduzir fragmentos desarticulados do conhecimento consagrado. Diante de tais circunstâncias é possível entender a dificuldade de se assumir como sujeto, o medo de contribuir para a definição de novos paradigmas e formular verdades, interpretações, [...] que alterem a lógica vigente.

Na ótica de Vergara (2004), o acesso ao conhecimento por meio da ciência tem na pesquisa uma atividade objetiva e subjetiva, discutível (afinal, ciência não é dogma), carregada de reflexões, contradições, sistematizações e re-sistematizações, que lhe dão vitalidade. Apesar dos procedimentos, técnicas, pressupostos e lógicas de investigação que emergiram nas últimas décadas, inúmeras avaliações disponíveis sobre a qualidade das pesquisas realizadas, no ensino superior, mostram que os resultados apresentados por esses estudos, nem sempre são confiáveis (ALMEIDA, 1977; ALVES-MAZZOTTI, 2004).

No entanto, o desenvolvimento das tecnologias da informação e da comunicação (TIC) e, em especial, o surgimento da Internet, trouxeram ao cenário educacional brasileiro uma nova preocupação em relação às pesquisas acadêmicas. Constantemente, surgem denúncias de sites de compra e venda de monografias (como, por exemplo, www.monografiasonline.com.br; www.tudopronto.com.br; www.zemoleza.com.br), e críticas severas à fidedignidade e relevância das informações veiculadas, no meio digital, ganham destaque na mídia.

Em face dessa realidade, alguns educadores levantam suas vozes, invocando a ética acadêmica e o respeito à propriedade intelectual, ao passo que outros defendem o acesso às informações e a do conhecimento. As duas posições, aparentemente antagônicas, trazem em si, as sementes da complementaridade, deixando à responsabilidade dos professores, a criação de mecanismos que possam inibir tais práticas. Nesse sentido, Silva (2001, web) advoga que:

[...] a verdade científica é um processo de transparência que vai desde a escolha do tema até a escolha dos instrumentos de coleta, análise dos dados e construção da linguagem. Logo, sendo a ciência um espaço de transparência e busca da verdade, ela não admite ocultamento intencional de quem se propõe a fazer ciência. E, sendo assim, a academia se difere do resto da sociedade porque sua finalidade é transformar o duvidoso, ambíguo e aparente, em leis e princípios claros, comprováveis e fundamentados. Na medida em que aceitamos a prática de ocultamento das verdades no seio da academia, estamos corroborando para uma prática danosa ao processo científico, que em essência é democrático, transparente e visível.

Como, então, evitar que os estudantes extraiam de sites publicados, ou da mídia em geral, fragmentos de textos de autores diversos, num processo de mera reprodução do já conhecido e sabido? Como garantir não apenas que os indivíduos, mediante um processo investigativo, construam o seu conhecimento, mas, e principalmente, atribuam maior valor à aprendizagem que ao ensino?

Neste artigo, as autoras buscam responder a essas questões, refletindo sobre os processos comumente adotados, e sugerem algumas estratégias com vistas à reversão dessas práticas, para que 'o faz-de-conta das pesquisas' possa dar espaço às demandas impostas pelo mundo digital.

É importante considerar que, no âmbito da formação acadêmica, esse tipo de estudo representa o vértice de um triângulo em cuja base se encontram métodos e estratégias eficazes de aprendizagem, que têm início nos 
primeiros anos de formação, e que poderiam favorecer o desenvolvimento da pesquisa científica nos cursos superiores.

\section{Da fragmentação do conhecimento à conexão em rede}

Vive-se, hoje, numa sociedade em rede, marcada por rápidas e profundas mudanças de todas as ordens, impulsionadas pelo desenvolvimento científico-tecnológico. Nessa nova realidade, as idéias, o pensar e a criatividade ganham relevo, e se constituem no diferencial das sociedades pós-modernas, cabendo às escolas, em geral, e às universidades, em particular, a responsabilidade de levar os indivíduos a se desenvolverem nessa direção. Assim, é preciso buscar novas soluções para antigas questões; pesquisar, discutir, refletir, decidir, resolver problemas, criticar, inova; e isso pressupõe uma ação responsável, por parte das pessoas, para a construção de seu próprio conhecimento e da coletividade. Quando esses elementos se fazem ausentes, a pesquisa concretiza-se como uma simples reprodução do conhecimento preexistente, sem qualquer tipo de contribuição pessoal do pesquisador.

De uma forma geral, tal prática é alimentada nas instituições de ensino, uma vez que: (a) enfatiza-se a aquisição de conteúdos, em detrimento de outros saberes, como os relacionados ao 'fazer' (prática) e ao 'ser' (atitudes); (b) o espaço destinado a discussões, reflexões e críticas acerca de fatos, eventos e fenômenos inerentes à sociedade contemporânea é bastante restrito; (c) há uma tendência generalizada de se associar 'pesquisa ou investigação científica' a procedimentos que não levam à construção do conhecimento e ao aprendizado, em geral; e, ainda, (d) o processo de ensino-aprendizagem é fragmentado, estruturado em disciplinas isoladas, deixando de considerar a interdisciplinaridade, com sérias implicações ao processo de criação (LIMA, 2004).

Numa época em que as verdades científicas são cada vez mais passíveis de reformulações, e o homem deve sintonizar-se com os artefatos científico-tecnológicos disponibilizados pela sociedade informacional, torna-se relevante que os sistemas educacionais compreendam o aluno como o centro da ação educativa. Como, no dizer de Lima (2004, p. 15), um "homem integral, movido pela razão e pela emoção, pelo consciente e pelo inconsciente, pela realidade e pela utopia, pela ação e reflexão, pelo trabalho e pelo ócio".

Para lidar com o mundo virtual, os indivíduos precisam desenvolver seu potencial reflexivo e crítico, ou seja, a capacidade de pensar, para obter o conhecimento. Anteriormente disponíveis, de forma impressa, em unidades especializadas, hoje a maioria das fontes de informação está presente na Internet, o que requer certos cuidados na interação com esse meio.

A importância de avaliar-se a informação disponível na Internet é bastante significativa para quem a utiliza com a finalidade de pesquisa, e é de extrema relevância para enfatizar a inconstância da qualidade das informações encontradas. [...]. As selecionadas para uso devem ser filtradas por critérios de avaliação que analisem tanto o conteúdo quanto a apresentação da informação (TOMAÉL, 2004, p. 19-20).

Transformar informação em conhecimento demanda percepção dos objetos, pessoas e eventos, e seus interrelacionamentos, o que implica desenvolver, nos estudantes, além de aspectos cognitivos, aqueles relacionados a habilidades e comportamentos.

Ao se referir à pesquisa, na vida acadêmica, Pádua (1988, p. 149) assim se expressa:

[...] o termo 'pesquisa' tem designado uma ampla variedade de atividades desde a coleta de dados para realização de seminários à realização de pastas-arquivo com recortes de jornais e revistas sobre um assunto escolhido pelo professor, ou mesmo uma forma de resumo, coleta indiscriminada de trechos de vários autores sobre um determinado tema, resultando numa 'colcha de retalhos' praticamente inútil ao processo de aprendizagem. 
Apesar de esse texto ter sido escrito há praticamente vinte anos, a situação descrita é bem atual, e vem sendo agravada com as facilidades oferecidas pela Internet, mediante compra e venda de 'trabalhos prontos', ou mesmo pela possibilidade de extraí-los num simples ato de 'copiar e colar'. É necessário, também, levar em conta que a expansão desenfreada do saber, com o volume de informações disponibilizadas pela mídia digital, escapa ao controle humano, o que requer organizar o conhecimento. Nesse contexto, diz Morin (1990) que a educação precisa buscar as contribuições da filosofia, aproximar-se da arte e explorar os recursos tecnológicos, a fim de que o aluno possa navegar no oceano de informações do ciberespaço, ampliando seus conhecimentos e sua competência relacional, comunicando-se, adequadamente, com pessoas e grupos, e construindo o seu próprio conhecimento, num processo de co-autoria.

Outro aspecto que colabora para essa prática é o não-alinhamento do sistema educacional à realidade e seus desafios, ao manter seus fundamentos na memorização de conteúdos, tendo como alicerces o sistema de notas e a fragmentação do ensino, o que acarreta dificuldade de articular diferentes conteúdos entre si, integrando-os e os contextualizando.

Ainda que a memorização de conteúdos venha sendo criticada por muitos educadores, que afirmam que o aprendizado requer compreensão e reflexão, ela continua sendo reforçada, quando suas aulas são baseadas na transmissão do conhecimento. Assim, instaura-se um ciclo vicioso, em que a leitura, a escrita, o pensar e as inter-relações são pouco estimulados. Torna-se, portanto, imperativo a busca de mecanismos inibidores desses comportamentos, ainda que coexistam duas mentalidades em paralelo: a que nos aponta a necessidade de se 'aprender a aprender'; e outra orientada para preparar os alunos para os exames vestibulares e/ou concursos públicos calcados, em geral, no processo de memorização. Apesar disso, ressalta-se que esses dois pensamentos não são divergentes: ambos preconizam o desenvolvimento de conteúdos.

Que caminhos, então, deverão ser percorridos para que o processo de aprendizagem não perpetue tais práticas? Como despertar, no educando, o gosto pela leitura e pela pesquisa, ajudando-o a compreender que tão importante quanto saber ler é construir o seu conhecimento, mediante atitude crítica no ato de ler?

A complexidade que envolve a busca de informações, especialmente na Internet, exige um investimento significativo em alternativas pedagógicas, em adição à tradicional forma de transmissão de conhecimentos, que despertem o interesse dos estudantes, promovam a interatividade, desafiem sua inteligência e incentivem o exercício da pesquisa acadêmica, com o intuito de possibilitar o entendimento da realidade que os cerca.

Urgem novas atitudes comunicacionais e curriculares/pedagógicas no ciberespaço que contemplem a ressignificação da autoria do professor e do estudante como co-autor. O currículo em rede online exige a comunicação interativa onde o saber e fazer transcendam as atitudes burocráticas que separam quem elabora, quem ministra [...] e quem recebe os pacotes de informações. (SANTOS, 2003, p. 218)

\section{A busca do conhecimento}

Educação e conhecimento são faces de uma mesma realidade. A transmissão de conhecimento torna-se inviável, na medida em que o ser humano, não sendo um mero objeto, interpreta o que vê ou sente. Maturana e Varela (1995); Varela (1997) afirmam que o indivíduo capta ativamente a realidade externa, impondo-lhe seu ponto de vista de observador. A transmissão do conhecimento também é criticada por Freire (1982) como o modelo mais utilizado no ensino e menos habilitado a educar, visto que não estimula a expressão criativa, e transforma o educando num mero receptor, que perdeu a capacidade de ousar.

Quem apenas fala e jamais ouve; quem 'imobiliza' o conhecimento e o transfere a estudantes, não importa se de escolas primárias ou universitárias; quem ouve o eco apenas de suas palavras, numa espécie de narcisismo oral [...], não tem realmente nada a ver com libertação nem democracia. (FREIRE, 1982, p. 30-31) 
A aquisição de conhecimento pressupõe um processo dinâmico de construção, desconstrução e reconstrução permanente, na busca dos resultados pretendidos. Nesse contexto, o pesquisador é um eterno aprendiz, que busca minimizar suas dúvidas, insegurança e ansiedade, sustentando suas interpretações e reflexões em contribuições de estudiosos e em resultados de estudos similares sobre o tema objeto de sua pesquisa. De acordo com as modernas teorias educacionais, a ocorrência da aprendizagem se realiza pelo esforço de reconstrução empreendido pelo aluno, e pela orientação do professor (DEMO, 2001). Assim, é tarefa central das instituições educacionais considerarem a pesquisa não apenas como princípio científico, mas como fundamento educativo.

Nesse novo modelo, os conhecimentos tramitam nas duas direções, promovendo o intercâmbio professor-aluno, em que ambos aprendem e ensinam, numa relação fluída: o professor dinamiza o processo de aprendizagem e o seu fazer pedagógico, e o aluno constrói seu próprio conhecimento.

Ressalte-se que a diversidade de definições e interpretações do que seja Ciência, ao longo da História, tem influenciado, sobremaneira, o resultado de pesquisas acadêmicas. Warde (1990, p. 70), referindo-se à questão da qualidade das pesquisas realizadas nos programas de pós-graduação, afirma que esse conceito foi tão ampliado, "a ponto de permitir que nele caibam os folclores, os sensos-comuns, os relatos de experiência (de preferência a própria) para não computar os desabafos emocionais e os cabotinismos".

Por sua vez, Demo (1994) diz que existem tantos acordos e polêmicas a respeito do que seja Ciência, que é legítima a conclusão de que a dúvida é parte integrante dela, sendo sua característica principal o questionamento sistemático, que valoriza, principalmente, o processo de elaboração argumentada - teórico e prático, e lhe confere a condição de meio ou de método.

Na sociedade contemporânea, em que o conceito tradicional de tempo e espaço ganhou uma nova dimensão, o ensino superior deve, sem desprezar o desenvolvimento de conteúdos, necessário ao exercício profissional, valorizar o domínio metodológico e pedagógico da pesquisa, direcionado ao saber pensar e 'aprender a aprender', respeitando as regras estabelecidas no seio do debate científico.

Assim, o redirecionamento dos métodos didáticos e a descoberta de novos caminhos fazem-se necessários. A Internet, se bem utilizada, tem muito a oferecer ao processo ensino-aprendizagem. Nessa perspectiva, colabora para a formação do aluno e favorece a construção do novo conhecimento e do aprendizado, que só advirão se ele puder pautar sua ação num material que tenha carga cognitiva interessante e lhe pareça significativo, possibilitando-lhe responder às inquietações provocadas pela assimilação desse material.

\section{Construindo o conhecimento na sociedade informacional}

Como um processo permanente de busca da verdade, que deve ser coerente, profundo e obedecer a uma lógica, além de legitimado pela comunidade acadêmica, a pesquisa vista como um instrumento metodológico para a construção e reconstrução do conhecimento e do aprendizado ganha uma dimensão central na atualidade (DEMO, 1997).

As instituições de ensino não mais detêm o monopólio do saber. O ensino via Internet exige que os professores revejam sua autoria na construção do conhecimento, para atuarem em um modelo de comunicação descentralizado e plural, em que a mensagem pode ser recomposta, modificada e reorganizada sob a intervenção do receptor, que se torna, de certa forma, criador, ao lhe dar significado, tendo como ponto focal o encontro do texto com o hipertexto.

A atividade de leitura, fundamental à obtenção de informações, da mesma forma que o hipertexto, funciona por meio de associações: uma palavra remete a conceitos e representações adquiridos ao longo da existência; implica uma busca, por parte do indivíduo, de alguma coisa na memória ou nos conhecimentos preexistentes; 
processo esse que guarda relações de similitude com o processo investigativo. Daí sua importância para o processo de pesquisa. Palangana (2002, p. 38) afirma que:

[...] com a linguagem, inclusive aquela veiculada em sala de aula, o sujeito adquire um conjunto de riquezas produzidas pelos próprios homens, dentre elas a consciência, que pode ser um fato alienado ou um forte instrumento na leitura de mundo e, mais que isso, um instrumento norteador de sua práxis na atual conjuntura.

Sob tal ótica, Bakhtin (1986) enfatiza o dinamismo da língua, evidenciado na comunicação entre os homens, no âmbito de uma variedade de textos e linguagens, em diferentes contextos sociais. Para ele, o princípio constitutivo da linguagem são as relações dialógicas, que ressaltam a relatividade da autoria individual, deixando em evidência o caráter coletivo, social, da produção de idéias. Assim, a leitura constitui-se num interdiscurso, que se realiza pelo cruzamento de diversos textos, ou seja, de outras vozes presentes na produção textual. A palavra não é só meio de comunicação, mas a expressão da própria consciência, e esta, sendo socialmente determinada, não impõe ao homem um comportamento meramente reprodutivo, mas lhe permite agir sobre seu contexto social, de forma criativa.

Assim, às competências técnicas e fundantes (aprendizagem da leitura, da escrita e números) devem-se acrescentar os conhecimentos de informática, para que o aluno os mobilize e os utilize adequadamente (ALARCÃO, 2001). Deve-se, ainda, possibilitar-lhe o desenvolvimento de competências de natureza comportamental, fundamentais no enfrentamento dos desafios impostos pelas rápidas transformações por que passa o mundo. Em relação ao termo 'competências', o Parecer 16/99 do Conselho Nacional de Educação registra:

A competência não se limita ao conhecer, mas vai além, porque envolve o agir numa situação determinada. O agir competente inclui decidir e agir em situações imprevistas, mobilizar conhecimentos, informações e hábitos, para aplicá-los, com capacidade de julgamento, em situações reais e concretas, individualmente e com sua equipe de trabalho. (CNE/CEB/PCNb, 1999, p. 32)

Desenvolver tais competências pressupõe um trabalho preliminar, dado que para se estabelecer relações entre idéias, fatos e fenômenos não basta simplesmente sistematizar o conhecimento. Nesse sentido, é fundamental que o professor, independentemente da disciplina ministrada, possa selecionar estratégias de aprendizagem que contemplem a cooperação e a interatividade, a fim de estabelecer um conjunto de relações entre indivíduo(s), grupo(s) e professor(es) e a conseqüente apropriação dessas competências pelos alunos. Estudos de casos, por exemplo, possibilitam ampliar a capacidade de observação, análise, inferência e juízo de valor. A aprendizagem por projetos, por sua vez, ajuda o estudante a melhor organizar as informações, conforme um problema ou hipótese relativos aos saberes apreendidos nas diferentes disciplinas e sua transformação em conhecimento próprio.

No Quadro 1, Lopes e Padilha (2006) apresentam algumas competências transversais que podem ser trabalhadas em qualquer disciplina:

Quadro 1- Matriz de Competências

\section{Identificar}

Destacar, reconhecer, apontar, indicar, determinar elemento ou elementos que pertencem a uma situação, processo, fenômeno etc.

\begin{tabular}{ll}
\hline Caracterizar & Indicar os atributos identitários de uma situação, processo, fenômeno etc. \\
\hline Diferenciar & Indicar diferenças entre situações, processos, fenômenos etc., distinguir \\
\hline Relacionar & $\begin{array}{l}\text { Indicar uma relação de semelhança ou de causalidade entre dois ou mais processos, } \\
\text { fenômenos, situações etc. }\end{array}$
\end{tabular}




\begin{tabular}{ll}
\hline Comparar & $\begin{array}{l}\text { Indicar várias relações de semelhança e de diferença entre dois ou mais processos, } \\
\text { fenômenos, situaçôes etc. }\end{array}$ \\
\hline Analisar & Relacionar criticamente \\
\hline Avaliar & Depois da análise, tomar uma decisão, emitir um julgamento final \\
\hline Coletar informações & Conhecer procedimentos de busca em diferentes fontes \\
\hline Selecionar informações & Distinguir informações relevantes e secundárias pertinentes ao tema em pesquisa
\end{tabular}

Fonte: Lopes, L.M.C.; Padilha, H. (2006, p. 187)

As tecnologias da informação e da comunicação (TIC) têm favorecido a utilização de estratégias modernas e desafiadoras, que estimulam o aluno a criar, recriar, interpretar diferentes contextos, criticar, analisar, sintetizar pontos de vista e comparar diferentes idéias, influenciando o processo de aprendizagem em todos os níveis e áreas de ensino - o que possibilita que as pessoas se interconectem e construam o conhecimento, interagindo virtualmente com o mundo ao seu entorno.

Como fundamento educativo, portanto, a pesquisa deve ser desenvolvida desde os níveis básicos, para que os estudantes, ao ingressarem no ensino superior, estejam conscientes da seriedade dessa prática. Para Demo (1997), alguns princípios essenciais à pesquisa devem ser incentivados, como por exemplo: (a) a explicitação do pensamento, mediante um processo dialógico; (b) a leitura não somente como compreensão da língua, mas também no seu sentido crítico e construtivo, que envolve interpretação própria; e (c) o questionamento reconstrutivo, baseado no diálogo, que consiste em:

[...] saber procurar material, interpretar e formular, pois para que seja superada a educação pela imitação é preciso aprender a aprender e esta se caracteriza pelo controle, reelaborando a argumentação; refazer com linguagem própria interpretar com autonomia; reescrever criticamente; elaborar texto próprio, experiência própria, formular proposta e contraproposta. (DEMO, 1997, p. 29)

Igualmente, o exercício da escrita favorece o desenvolvimento da argumentação, com base na co-autoria; isso é, a reconstrução coletiva de um texto, tendo alguma elaboração própria. Moraes, Ramos e Galiazzi (1999) enfatizam que o processo de pesquisa envolve três componentes: o questionamento, a construção de argumentos e a validação dos resultados, todos eles mediados pelo diálogo crítico dos pares. A pesquisa não separa a ação de conhecer da ação de atuar. O pesquisador é coletivo; os saberes emergem na relação entre sujeitos.

Silva (2003) afirma que o uso de tecnologias e interfaces digitais potencializam o diálogo, a autoria coletiva e o compatilhamento de sentidos nos diferentes tipos de linguagens e mídias. Dessa forma, o processo de pesquisa em educação online deve partir da concepção de estratégia, caracterizada por uma rede de relações, de onde emergem diferentes autorias possibilitadas pela associação entre teoria, prática e tecnologia digital. A esse respeito, Peters (2004, p.171), escreve:

Os alunos lucram aqui com um aumento da autonomia, porque eles podem eles mesmos selecionar os caminhos de aprendizagem baseando-se em seus próprios interesses e associações, por sua própria conta e segundo sua própria estratégia (espaço de exploração). Idealmente, cada estudante pega seu próprio caminho de aprendizagem, que não é usado por mais ninguém. Isso torna o hipertextohipermídia um instrumento eficaz para individualizar caminhos de aprendizagem e ao mesmo tempo uma pré-escola e uma escola para a aprendizagem autônoma.

Nesse contexto, as ferramentas da Internet, nas formas síncrona e assíncrona, são relevantes instrumentos, que permitem ao educando desenvolver a pesquisa e exercitar, no coletivo, sua individualidade, e contribuem para sua autonomia. As interfaces digitais utilizadas como canais de comunicação interativos, voltados para a criação e autoria, constituem espaços formativos, verdadeiros laboratórios de textos e narrativas, passíveis de 
experimentações de diversos formatos, tais como os fóruns de debate, os chats, os blogs e diários online, os portfólios e o webquest.

Os fóruns são usados para mediar a comunicação assíncrona entre os sujeitos da comunicação, que postam suas mensagens sobre temas propostos como provocação à participação, expressando suas opiniões, argumentando, contra-argumentando e tirando dúvidas. Permitem "a construção, estruturação, organização e registro das narrativas e autorias dos sujeitos a partir da multiplicidade e pluralidade de seus discursos" (SANTOS, 2006, p.133).

Os chats possibilitam a comunicação de 'todos para todos', em tempo real, com o envio e recepção de mensagens textuais ou icônicas, de forma simultânea. Permitem discussões temáticas e produções colaborativas, mediadas ou não, que estreitam as relações e promovem a aprendizagem. $\mathrm{O}$ texto neles produzidos é quase sempre "telegráfico, ligeiro, não-linear, próximo da linguagem oral, efervescente e polifônico num jogo semiótico complexo" (SILVA, 2003, p. 65). Isso torna a comunicação caótica e hipertextual, dificultando a sincronia e resultando em contribuições superficiais. Contudo, é importante valorizar o fato de os indivíduos dialogarem, de forma livre e plural, nesses espaços.

Blogs e diários online permitem criar, publicar e manter atualizadas mensagens em tempo real. Os blogs voltados para a pesquisa são uma espécie de diário de campo, que permitem a descrição densa de fenômenos, eventos e pessoas, resultante da leitura da realidade dos contextos em que se realiza a pesquisa e de suas dimensões interpretativas e simbólicas. O espaço de um blog passa a ser o de trocas, onde os indivíduos podem compartilhar seus dilemas e saberes, interagindo com outros indivíduos. Sua utilização pode despertar, no estudante, a vontade de aprender, favorecendo a interatividade, o trabalho em grupo e o desenvolvimento do pensamento crítico. No entanto, deve ser aplicado de forma adequada, com base em pressupostos pedagógicos que orientem sua prática.

Os portfolios consistem num dispositivo destinado ao armazenamento das produções desenvolvidas pelo educando. Proporcionam, ao mesmo tempo, uma visão ampla e detalhada da aprendizagem efetuada, bem como dos diferentes componentes do seu desenvolvimento cognitivo, metacognitivo e afetivo. Permitem, ainda, que tais produções possam ser compartilhadas com todo o grupo. O educando é, ao mesmo tempo, autor e avaliador de seus próprios trabalhos e dos de seus pares.

Os webquests, por sua vez, muito utilizados em pesquisas acadêmicas, são basicamente, ferramentas que permitem (re) construir o conhecimento, de forma investigativa; estimulam o desenvolvimento do pensamento crítico, uma vez que a proposta educacional baseia-se em desafios e situações-problema; incentivam a busca e a troca de informações entre os agentes envolvidos no processo, possibilitando o desenvolvimento da criatividade e a interação entre eles. Ressalte-se, ainda, que esses recursos permitem trabalhar a interdisciplinaridade, enriquecendo o processo ensino-aprendizagem.

Larsen (2000) afirma que tanto a informação como a diversão são objetos de consumo que todos esperam obter. Entretanto, o conhecimento não pode ser obtido e, sim, construído mediante esforço pessoal. Emerge daí o cuidado que o professor deve ter no momento de conceber e construir um webquest para propor uma pesquisa na Internet, sendo fundamental estabelecer as diretrizes básicas em relação aos objetivos didáticos esperados, que devem conter alguns dos seguintes atributos básicos:

1. Uma introdução que prepare o 'palco' e forneça algumas informações de fundo;

2. Uma tarefa factível e interessante;

3. Um conjunto de fontes de informações necessárias à execução da tarefa. Muitos (não necessariamente todos) dos recursos estão embutidos no próprio documento da WebQuest em forma de âncoras que indicam fontes de informação na Web. As fontes de informação podem ser: especialistas disponíveis via e-mail ou conferências on line, base de dados pesquisáveis na rede, livros e/ou documentos (arquivos) acessíveis no ambiente de aprendizagem. 
4. Uma descrição do processo que os aprendizes devem utilizar para efetuar a tarefa. O processo deve estar dividido em passos claramente organizados e descritos.

5. Alguma orientação sobre como organizar as informações adquiridas. Isto pode aparecer sob a forma de questões orientadoras ou como direções para completar as metas estabelecidas no prazo. 6. Uma conclusão que encerre a investigação, demonstre aos alunos o que eles aprenderam e, talvez, os encoraje a levar a experiência para outros campos não explorados dentro da WebQuest. (MUELLER, 2006, web apud DODGE, 1995)

Ressalte-se que estas e outras interfaces digitais podem despertar a curiosidade e o gosto pela leitura e pela escrita, potencializar a autonomia na aprendizagem e, em consequiência, a autoria. Entretanto, Bianchini (2003, p. 35) alerta que:

[...] a tecnologia, sozinha, não resolve os problemas educacionais como um todo, mas pode ser uma importante aliada na busca de qualidade, na luta contínua que deseja aumentar oportunidades $e$ resgatar as possibilidades concretas de universalidade e educação de qualidade para todos.

O uso dessas ferramentas e estratégias pressupõe que o professor compreenda como a 'geração net' ${ }^{3}$ aprende e como se estrutura seu pensamento, atuando como um estrategista da aprendizagem, revendo referenciais e métodos de leitura e escrita que possibilitem trabalhar a intertextualidade, tendo em vista ampliar no educando sua visão de mundo, preparando-o para o processo de investigação. Por isso, ao contrário do que se imagina, é tão importante que esse percurso comporte momentos e ambientes pedagógicos que favoreçam a participação ativa e responsável dos estudantes nas práticas de pesquisa, desde os primeiros níveis de formação e não somente na universidade.

\section{Rumo à pesquisa acadêmico-científica}

Demo (1990) afirma que o desenvolvimento da pesquisa do ponto de vista educativo é fundamental para o entendimento de que teoria e prática não podem ser vistas em separado, o que requer mais que o simples compromisso dos indivíduos, ou seja, exige seu envolvimento. É preciso que os alunos participem ativamente de todo o processo, na busca do conhecimento preexistente, para construir novos argumentos e contraargumentos. É necessário, ainda, que busquem a disciplina e a autonomia, aprendam a tomar decisões, escrevam seus projetos de pesquisa e seus relatórios, participem de debates, dialoguem com seus pares e professores; enfim, que se percebam como sujeitos agentes de produção de conhecimento e de sua aprendizagem.

Como fundamento científico, a pesquisa consiste num processo que objetiva compreender, interpretar e resolver um problema específico, para o qual se busca uma resposta, e exige do pesquisador um conjunto de atitudes que estimule seu amadurecimento pessoal e intelectual. Envolve aspectos relacionados ao planejamento e à operacionalização de um determinado tema/problema, mediante um exercício sistemático de produção do conhecimento, além de contribuir para a formação de profissionais, cidadãos e homens.

A elaboração de uma pesquisa pressupõe a escolha de temas significativos discutidos e acordados com os educandos, e alicerçados em valores e princípios, tais como:

a) o princípio da dúvida, como forma de abrir, problematizar e construir o conhecimento;

b) o espírito democrático; o respeito às diferenças;

c) o incentivo à reflexão e à crítica na análise da realidade individual e social;

d) o desenvolvimento da cooperação e da colaboração; ${ }^{3}$ São os filhos da idade digital, de uma revolução das comunicações que está a moldar uma nova geração e o seu mundo, um fenômeno
jamais visto. www.janelanaweb.com/geracao/dtlivro.html 
e) o debate aberto e fundamentado, e o estímulo à participação.

De acordo com Ruiz (1996), o conhecimento científico implica capacidade de analisar, explicar, desdobrar, justificar, induzir, aplicar leis e predizer. Portanto, tem suas bases, na Ciência, que, por sua vez, está comprometida com a busca metódica da verdade, no intuito de ampliar os limites do conhecimento, de modo a agregar maior qualidade à existência humana. Dessa forma, a concretização de uma pesquisa científica pressupõe a utilização de um método científico, o que implica utilizar adequadamente a reflexão e a experimentação, evidenciadas em um conjunto ordenado de seqüências operacionais, essencial ao processo de investigação.

A formalização de uma pesquisa acadêmico-científica exige um projeto norteador, investimento em tempo e energia, capacidade de fazer, desfazer e refazer tarefas, e comprometimento com os resultados a serem obtidos. Não existe um só modelo de projeto; sua escolha depende do problema para o qual se buscam respostas, do método a ser utilizado, do tipo de pesquisa a ser desenvolvida, da visão de mundo do pesquisador, entre outras variáveis. Entretanto, qualquer que seja o modelo adotado, há certos elementos que não podem estar ausentes em seu desenvolvimento, como, por exemplo, a introdução, com a finalidade de contextualizar com clareza o tema e o problema motivador da investigação; a definição dos objetivos a serem alcançados e das questões norteadoras do estudo; a apresentação de uma revisão da literatura que embase o estudo; a metodologia a ser adotada; o cronograma das atividades; e as referências. A variação fica por conta dos conteúdos desses itens (VERGARA, 2004). A consolidação da pesquisa, propriamente dita, é feita mediante um relatório em que, além desses elementos, são apresentados os resultados e as conclusões do estudo e sugestões para novas pesquisas.

No universo das pesquisas realizadas nos cursos de pós-graduação, constata-se que, em geral, a abordagem é de natureza descritiva e/ou exploratória, sem o respaldo de uma base teórico-metodológica que lhe dê sustentabilidade e permita que as reflexões, ali presentes, sejam aplicadas a outros contextos. Essa deficiência também se reflete nos quadros teóricos de dissertações e teses, como afirma Alves-Mazzotti (2004, p. 144).

[...] em relação à pesquisa acadêmica, no Brasil, as inúmeras avaliações disponíveis apresentam muitos pontos em comum, entre os quais destacam-se: (a) pobreza teórico-metodológica na abordagem dos temas de pesquisa, com grande número de estudos puramente descritivos elou exploratórios; (b) pulverização e irrelevância dos temas escolhidos; (c) adoção acrítica de modismos na seleção dos quadros teórico-metodológicos; (d) preocupação com a aplicabilidade imediata dos resultados; e (e) divulgação restrita dos resultados e pouco impacto sobre as práticas.

Para garantir que as pesquisas sejam consideradas como um processo cumulativo de produção de conhecimento, construído coletivamente, é necessário, na tarefa de realizá-la, adotar critérios claros e métodos de investigação precisos, que descartem as ilusões de ótica, preconceitos, crenças, e superstições, em geral. Vergara (2005, p.10) também ressalta que "cabe ao pesquisador escolher o método mais adequado à(s) teoria(s) que suporta(m) seu estudo, ao problema que suscitou sua investigação e o fará dentro de seus pressupostos epistemológicos".

Nesse contexto, as instituições de ensino superior desempenham um papel de grande relevância ao assumir o compromisso de propiciar formação acadêmica de alto nível, identificando e aplicando estratégias de ensino que contribuam para o aprimoramento do estudante como profissional e cidadão. Para isso, argumenta Lima (2004), essas instituições devem, entre outras ações:

a) melhorar o nível de qualidade dos cursos oferecidos;

b) instrumentos técnicos, conceituais, teóricos e metodológicos inerentes à pesquisa sistematizada, para que o estudante-pesquisador aplique os conhecimentos desenvolvidos durante o curso na exploração de uma questão/dúvida ou problema relevante;

a) possibilitar, ao estudante aprofundar conhecimentos de seu interesse, participando de programas de pesquisas curriculares e/ou extracurriculares; 
b) fortalecer as bases de sua produção mediante um exercício permanente de reflexão e crítica sobre a realidade do País, pela investigação metódica de um tema relevante;

c) estimular o estudante a desenvolver atitudes mais profissionais, de disciplina, autonomia, ética e seriedade necessárias ao exercício da pesquisa;

d) valorizar e imprimir qualidade técnico-científica ao trabalho de conclusão de curso, com o objetivo de contribuir efetivamente na formação acadêmica do estudante;

e) horizontalizar a relação professor (orientador) / aluno (estudante-pesquisador), estimulando a interatividade;

f) promover eventos educativos, publicar os melhores relatórios de pesquisa, difundir seus cursos tanto para o meio acadêmico como para o meio empresarial e a comunidade em geral, com base na contribuição e na qualidade dos resultados obtidos;

g) instrumentalizar o estudante-pesquisador para as etapas subseqüentes de sua formação, a fim de que, de posse do arsenal teórico-metodológico, possa conceber e executar projetos compatíveis com a realidade em que atua;

h) oferecer experiências que, de uma forma geral, levem o indivíduo a se posicionar como eterno aprendiz, compromissado com o desafio da educação permanente.

A pesquisa científica exige do indivíduo um conjunto de atitudes proativas, que possibilita seu amadurecimento pessoal, intelectual e profissional, na medida em que o impele a exercitar a interpretação, a compreensão e a buscar soluções para os problemas. Entendida dessa forma, tanto a elaboração de um trabalho de conclusão de curso, como, também, toda produção acadêmica desempenham funções importantes, pois requerem a aplicação de conceitos acumulados, a solução de situações-problemas e a capacidade de planejar, organizar e operacionalizar um estudo específico sobre determinado tema, eliminando a simples reprodução do já visto e aprendido, rumo à produção efetiva do conhecimento.

Alves Mazzotti (2004, p.188) assinala o relevante papel do professor-orientador, no esforço de (re)direcionar a investigação, com vistas a agregar valor aos relatórios apresentados, especialmente no que se refere à revisão da literatura, dado que "textos repetitivos, rebuscados, desnecessariamente longos ou vazios afastam rapidamente o leitor não cativo, por mais que o assunto lhe interesse". Severino (2001, p. 56) compartilha desta opinião e argumenta que:

O professor universitário precisa de consolidada experiência de pesquisa para bem ensinar; o aluno da universidade precisa da prática investigativa para bem aprender. Com efeito, o estudante precisa fundar seu aprendizado num criterioso processo de construção do conhecimento, o que só pode ocorrer se ele conseguir aprender apoiando-se constantemente numa atividade de pesquisa, praticando uma atividade investigativa.

\section{Conclusão}

A partir da constatação de que, em geral, as práticas de pesquisa utilizadas nas instituições de ensino superior não atendem às demandas da educação e da pós-modernidade, o artigo discutiu a necessidade de o processo de pesquisa acadêmico-científica ter início nos primeiros anos de formação, dado que sua elaboração requer um trabalho de base, em que a integração ensino/pesquisa assuma relevância no desenvolvimento de competências e na construção e reconstrução de conhecimentos por parte do educando. Alguns pontos são levantados no desenvolvimento deste artigo para uma reflexão mais aprofundada sobre as práticas pedagógicas vigentes e o papel das tecnologias digitais, no processo de investigação.

Enfatiza-se que a iniciação do educando nos caminhos da pesquisa passa pela incorporação de estratégias de ensino que busquem despertar-lhe a curiosidade, a criatividade e o interesse pelo ensino, tendo o 'desafio da descoberta' como condição essencial para o desenvolvimento de sua capacidade de expressão e elaboração. 
Alerta-se para a urgência de uma mudança cultural, que possibilite ao educando desenvolver suas potencialidades e fundamentar seu aprendizado num criterioso processo de construção do conhecimento, alicerçado na leitura e na escrita, na resolução de problemas, no questionamento, na argumentação; uma ambientação que privilegie a reflexão e a crítica, sustentadas por uma visão interdisciplinar e por uma relação dialógica, no intuito de educá-los para a emancipação.

Outro ponto de destaque é a importância das TIC para o ensino-aprendizagem por estimular a produção coletiva do conhecimento pelos participantes da rede, em contraposição às práticas tradicionais, inibidoras dos processos criativos. Ressalta-se, ainda que a simples relação do educando com as mídias não garante a aprendizagem, não enseja a autoria, nem desenvolve o pensamento crítico. É essencial estimulá-lo a buscar sua própria identidade, o seu próprio estilo, aquilo que o distingue dos outros, para que possa se desvencilhar da reprodução automática das informações e se aventurar à descoberta da 'verdade', resultante de processos de investigação.

Nessa perspectiva, a utilização de recursos disponíveis na Internet, como os fóruns de debates, os blogs e diários online, os chats, os portfolios e os webquests, entre outros, favorecem o desenvolvimento de competências intelectuais e atitudes proativas de colaboração e cooperação, capazes de viabilizar a construção do conhecimento e/ou a utilização do conhecimento produzido.

A pesquisa acadêmico-científica como um processo de concretização de uma investigação planejada, redigida em consonância com normas metodológicas aceitas pela ciência, implica ruptura com o 'faz-de-conta', ou seja, com a mera reprodução do já conhecido e aprendido, num processo de 'copia e cola', sem qualquer intervenção analítica por parte do educando, que tem seu clímax na universidade, contribuindo para que o aluno, diante do desafio de elaborar esse tipo de estudo, não se considere responsável pelo produto apresentado.

Vale dizer que o alcance desse objetivo só será possível quando os sistemas educacionais como um todo transcenderem seus muros, rompendo velhos paradigmas consolidados pelo imediatismo, pela falta de visão de futuro e pelo medo do novo. Sua tarefa permanente deverá privilegiar a mudança de seu modo de pensar, a reorganização de seu trabalho, o incentivo à colaboração, o espaço para a pesquisa e o aprendizado e, em especial, o questionamento acerca de quais competências devem ser perseguidas para que os indivíduos possam participar dessa sociedade moderna, exigente e seletiva, dispondo de instrumentais que lhes possibilitem construir seu próprio caminho, dado que este se faz caminhando. 


\section{Referências}

ALARCÃO, I. Alunos reflexivos, numa escola reflexiva. Porto Alegre: Artmed, 2001 cap. 1. p. 12-39.

ALMEIDA, R. A. A avaliação das teses de mestrado na área de educação no Estado do Rio de Janeiro. Rio de Janeiro, 1977. (mimeo).

ALVES-MAZZOTTI, A. J. Revisão da bibliografia. In: ; GEWANDSZNAJDER, F. 0 método nas ciências naturais e sociais: pesquisa quantitativa e qualitativa. 2 ed. São Paulo: Pioneira, 2004.

BAKHTIN, M. Marxismo e filosofia da linguagem. São Paulo: Hucitec,1986.

BIANCHINI, D. SALVI - sala de aula virtual: contribuição para a comunicação síncrona em educação mediada por computador. Campinas: São Paulo, 2003.

CONSELHO NACIONAL DE EDUCAÇÃO. Câmara de Educação Superior. Resolução CNE/CES 1/2001. Diário Oficial da União, Brasília, 9 de abril de 2001.

. CNE/CEB. Parecer no 16/99, PCN, 1999.

DEMO, P. Pesquisa: princípio científico e educativo. São Paulo: Cortez, 1990.

Introdução à metodologia da ciência. São Paulo: Atlas, 1994.

Pesquisa e construção de conhecimento: metodologia científica no caminho de Habermas. Rio de Janeiro: Tempo Brasileiro, 1997.

Pesquisa: princípio cientifico e educativo. 10 ed. São Paulo: Cortez, 2001.

DODGE, B. WebQuests: a technique for Internet - based learning. The distance educator. 1995 v.1, no 2. Trad. Jarbas Novelino Barato.

FREIRE, P. A importância do ato de ler. São Paulo, SP: Autores Associados/Cortez, 1982.

LARSEN, S. Aspectos sociais e psicológicos das tecnologias educacionais. Florianópolis: 2a Jornada Catarinense de Tecnologia Educacional, 17 a 18 de agosto de 2000.

LIMA, M. C.. Monografia: a engenharia da produção acadêmica. São Paulo: Saraiva, 2004.

LOPES, L.M.C.; PADILHA, H. Estruturação de atividades didáticas baseadas na web a partir de uma matriz de competências. In: SANTOS, E.; LYNN, A. (Orgs.) Práticas pedagógicas e tecnologias digitais. Rio de Janeiro: E-papers, 2006.

MATURANA, H.; VARELA, F. De máquinas y seres vivos - autopoiesis: la organización de lo vivo. Santiago: Editorial Universitaria, 1995.

MARTINS, G. A; LINTZ, A. Guia para elaboração de monografias e trabalhos de conclusão de curso. São Paulo: Atlas, 2000.

MORAES, R.; RAMOS, M.; GALIAZZI, M. C. A pesquisa em sala de aula. CASE, 2, 04 a 08 de outubro de 1999, Curitiba. (Módulo temático).

MORIN, E. Introdução ao pensamento complexo. Lisboa, 1990.

PÁDUA, E. M. M. de. O trabalho monográfico como iniciação à pesquisa. In: CARVALHO, M.C. M. Construindo o saber: técnicas de metodologia científica. Campinas: Papirus, 1988.

PALANGANA, I. C. Trabalho, linguagem e consciência: uma mediação que fundamenta a prática escolar. In: BIANCHETTI L. (Org.). Trama e texto: leitura crítica; escrita criativa. 2 ed. São Paulo: Summus, 2002.

PETERS, O. A educação a distância em transição. São Leopoldo: Unisinos, 2004. 
SANTOS, E. O. dos. Articulação de saberes na EAD online; por uma rede interdisciplinar e interativa de conhecimentos em ambientes virtuais de aprendizagem. In: SILVA, M. (Org.). Educação online. São Paulo: Loyola, 2003.

. Educação on-line como campo de pesquisa-formação: potencialidades das interfaces digitais. In: ; LYNN, A. (Orgs.). Práticas pedagógicas e tecnologias digitais. Rio de Janeiro: E-papers, 2006.

SEVERINO, A. J. Consolidação dos cursos de pós-graduação em educação: condições epistemológicas, políticas e institucionais. In: ; FAZENDA, O. C. A. Conhecimento, pesquisa e educação. Campinas/SP: Papirus, 2001.

SILVA, M. Criar e professorar um curso online: relato de experiência. In: (Org.). Educação online. São Paulo: Loyola, 2003.

SILVA, M. B. A autoria e a responsabilidade científica. 2001. Disponível em http://www.comciência.br. Acesso em 22 nov. 2007.

RUIZ, J. A. Metodologia científica: guia para eficiência nos estudos. São Paulo: Atlas, 1996.

TOMAÉL. M. I.; VALENTIN, M. L. P. (orgs.) Critérios de qualidade para avaliar fontes de informação na Internet. Londrina: Eduel, 2004.

VARELA, F. J. et al. The embodied mind - cognitive science and human experience. Cambridge, Massachusetts: The MIT Press, 1997.

VERGARA, S. C. Projetos e relatórios de pesquisa em administração. São Paulo: Atlas, 2004. Métodos de pesquisa em administração. São Paulo: Atlas, 2005.

WARDE, M. J. O papel da pesquisa na pós-graduação em educação. Cadernos de Pesquisa. São Paulo: Fundação Carlos Chagas/Cortez, mai. 1990, n. 73, p. 67-75. 